\title{
Filter/moderator system for a BNCT beam of epithermal neutrons at nuclear reactor MARIA
}

\author{
Institute of Atomic Energy, 05-400 Otwock-Swierk, Poland \\ e-mail: kasia.tyminska@gmail.com
}

\begin{abstract}
Boron Neutron Capture Therapy is a very promising form of cancer therapy, consisting in irradiating a stable isotope of boron $\left({ }^{10} \mathrm{~B}\right)$ concentrated in tumor cells with a low energy neutron beam. This technique makes it possible to destroy tumor cells, leaving healthy tissues practically unaffected. In order to carry out the therapy in the proper way, the proper range of the neutron beam energy has to be chosen.

In this paper we present a filter/moderator system modeled with MCNP code in order to obtain an epithermal neutron beam for BNCT post at MARIA reactor in Swierk.
\end{abstract}

Key words: BNCT, Boron Neutron Capture Therapy.

\section{Introduction}

BNCT (Boron Neutron Capture Therapy) is a form of radiotherapy that held promise of being beneficial to cancer patients with glioma, a type of brain cancer. This type of tumor is quite resistant to other treatment modalities and the prospects of its cure are very poor.

An ideal therapy for cancer would be one whereby all tumor cells were selectively destroyed without damaging normal tissues.

BNCT brings together two components that, when kept separate, have only minor effects on cells. The first component is a stable isotope of boron (boron-10) that can be concentrated in tumor cells by being attached to tumor-seeking compounds. The second one is a beam of low-energy neutrons. Boron-10 in or adjacent to tumor cells 
disintegrates after capturing a neutron. The high-energy, heavy charged particles, produced in the nuclear reaction, destroy only the cells in close proximity to the vertex, which are primarily cancer cells, leaving adjacent normal cells largely unaffected.

If the tumor tissue is situated in the brain at a depth of about 2-3 cm, the most usable are epithermal neutrons with energy of approx. $1 \mathrm{keV}$ [1]. Those neutrons are moderated in the tissue between the skin and the tumor cells and they obtain thermal energies (below $0.5 \mathrm{eV}$ ), when reaching the tumor tissue (the cross-section for the reaction with ${ }^{10} \mathrm{~B}$ is inversely proportional to the neutron velocity). Direct irradiation with thermal neutron beam would cause a big irradiation of the healthy tissue on the surface and too few neutrons reaching the tumor tissue.

In case of neutrons coming from a nuclear reactor MARIA at the Institute of Atomic Energy Swierk, the only method to obtain a beam of neutrons with energies from the chosen range is using a system of moderators and filters, together with a converter containing ${ }^{235} \mathrm{U}$.

The narrower range of energy we want to obtain, the thicker filter is needed. Unfortunately, using a filter of bigger thickness causes decreasing of neutron flux in all the energy scope, including the range we want to keep maximum.

\section{The model}

In order to obtain the optimum energy range, a filter was designed, using the MCNP Monte Carlo code.

The filter was defined as a cylindrical solid of $60 \mathrm{~cm}$ diameter corresponding to the diameter of channel H-2 of MARIA reactor. The flank surface was defined as $1 \mathrm{~mm}$ thick $\mathrm{Cd}$ layer, used in order to capture low energy neutrons coming from scattering in concrete wall of the channel. Such a layer, made of cadmium plate is a very effective low energy neutron filter.

The source of neutrons was defined as a circular surface, $15 \mathrm{~cm}$ diameter, in $20 \mathrm{~cm}$ distance from the cylinder axis, what corresponds to the situation of the tube, connecting the reactor core with the H-2 channel.

The distance of 135 centimeters between the core and the channel allows the assumption, that all the neutrons are emitted perpendicularly to the surface. The energy spectrum of the source was taken from MCNP calculations using the model of MARIA reactor core with converter, described in [2]. 


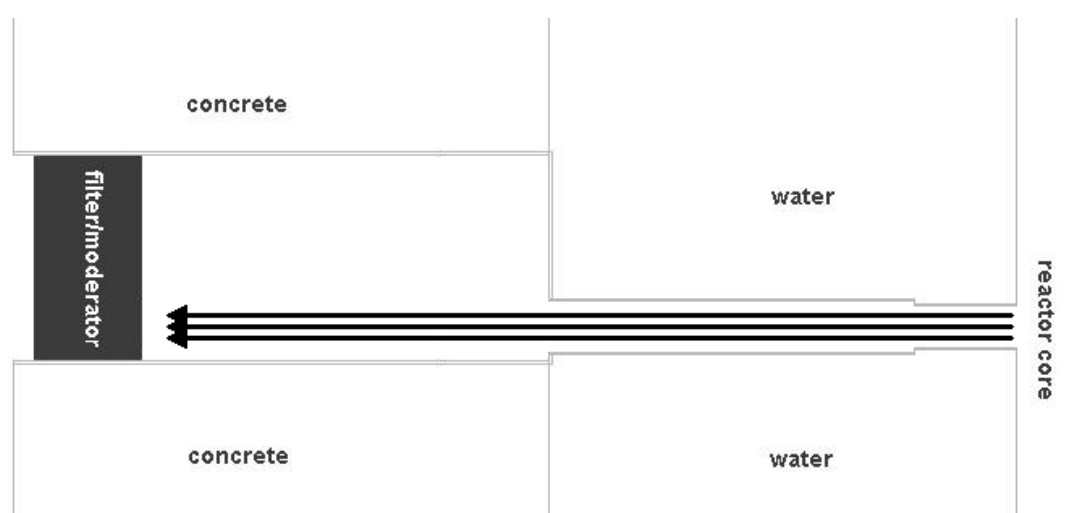

Figure 1. Diagram of the modeled system. The gray lines are to present the situation of filter in the reactor channel, they aren't included in the filter simulation code.

A number of materials used in reactor filters for BNCT therapy were investigated, making it possible to choose the optimum configuration.

\section{Results and discussion}

The filter was constructed layer by layer, observing the influence of each layer on the spectrum and comparing the results for various materials and their thickness.

The first layer of the filter/moderator system was planned to be a moderating layer and in such cases it is typical to use one of such materials like $\mathrm{H}_{2} \mathrm{O}, \mathrm{D}_{2} \mathrm{O}$, polyethylene, graphite or beryllium. Of the tested materials $\mathrm{D}_{2} \mathrm{O}$ seems to be the best for BNCT purposes reducing effectively the number of fast neutrons and increasing the number of neutrons in epithermal range (Figure 2).

The influence of such materials on the spectrum shape is indisputable, but it is leveled by the influence of the next layer, that was chosen to be made of (natural) lithium fluoride.

LiF seems to be very promising, because it effectively captures neutrons of low energies, below $10 \mathrm{eV}$, and reduces the number of neutrons of energies above approx. $10 \mathrm{keV}$. Figure 3 presents the comparison of the spectra obtained by using three different one-layer filters made of natural $\mathrm{LiF}(30 \mathrm{~cm}$ and $35 \mathrm{~cm}),{ }^{6} \mathrm{LiF}(35 \mathrm{~cm})$, and one two-layer filter $\left(5 \mathrm{~cm} \mathrm{D}_{2} \mathrm{O}+30 \mathrm{~cm} \mathrm{LiF}\right)$. The plot shows, that adding $5 \mathrm{~cm}$ of $\mathrm{LiF}$ to $30 \mathrm{~cm}$ has almost the same effect as adding $5 \mathrm{~cm}$ of heavy water, the number of fast neutrons is 


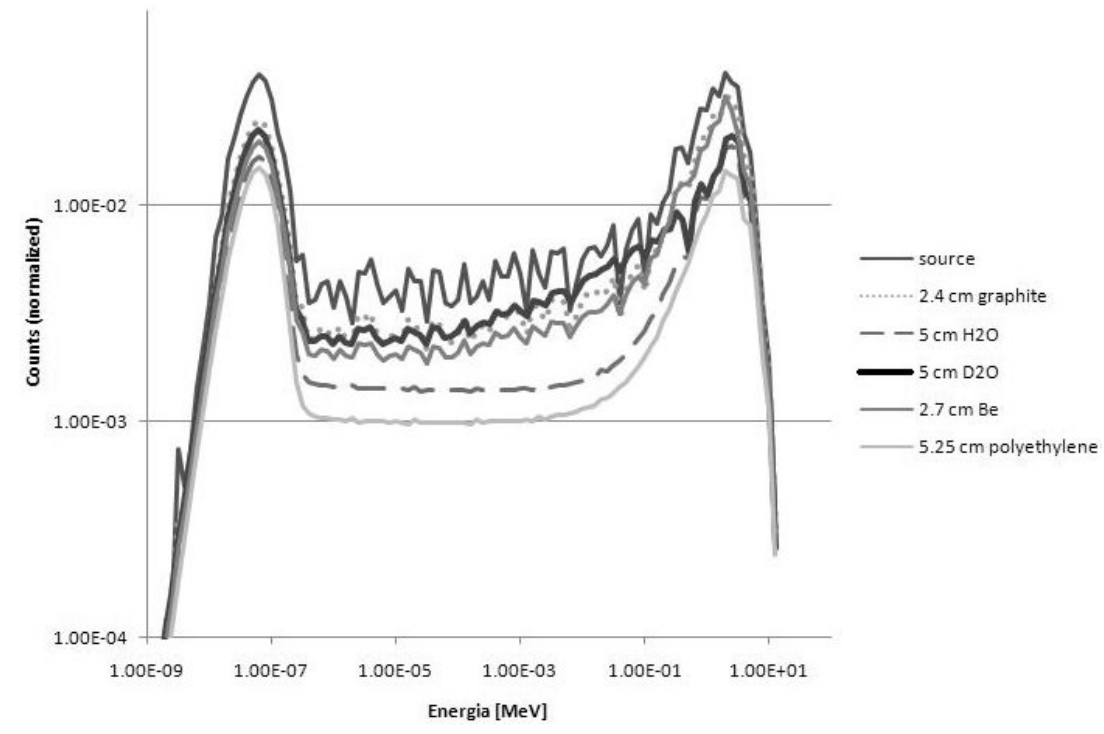

Figure 2. The influence of a layer of a material of popular moderators. For the comparison reasons the thickness was chosen to keep the product of density and thickness constant. The widest line corresponds to $\mathrm{D}_{2} \mathrm{O}$.

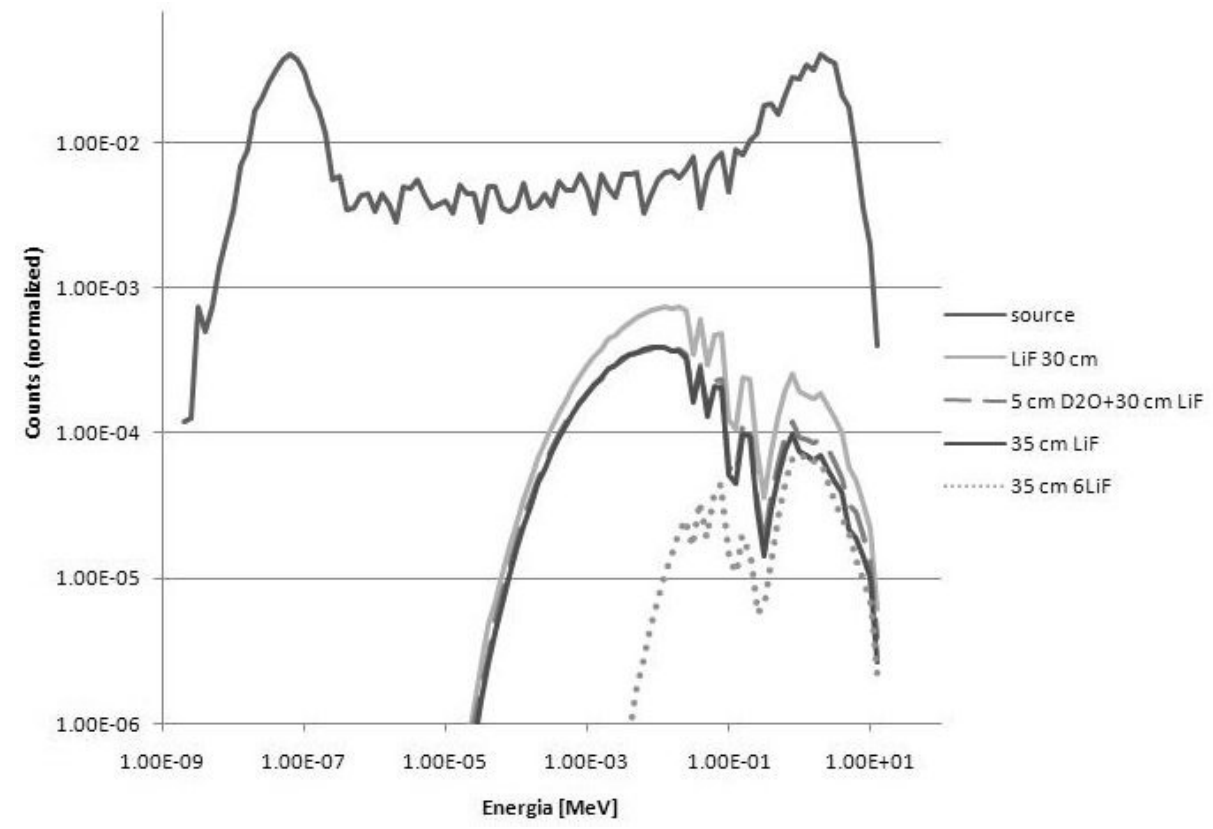

Figure 3. The comparison of neutron spectra from filters made of $\mathrm{LiF},{ }^{6} \mathrm{LiF}$ and $\mathrm{D}_{2} \mathrm{O}+\mathrm{LiF}$. 
even slightly lower for LiF. ${ }^{6}$ Lif with higher cross section for neutron caused reactions reduces the number of epithermal neutrons rather than the fast ones, therefore it is not a suitable material for BNCT purposes.

The thicker the LiF layer, the higher is the ratio of epithermal to fast neutrons (thermal neutrons are all captured), but also the epithermal neutrons number decreases, due to capture in material and escape through the flank surface of the filter, therefore the thickness should be carefully chosen in order to obtain best energy range quality when keeping the neutron flux sufficient.

The material commonly used in BNCT filters in order to decrease the number of fast neutrons is $\mathrm{Al}$ or its compounds. In our calculations we have compared the influence of $40 \mathrm{~cm}$ of Al and $40 \mathrm{~cm}$ of $\mathrm{AlF}_{3}$ placed after a layer made of $35 \mathrm{~cm}$ of $\mathrm{LiF}$ with $55 \mathrm{~cm}$ of $\mathrm{LiF}$ (Figure 4).

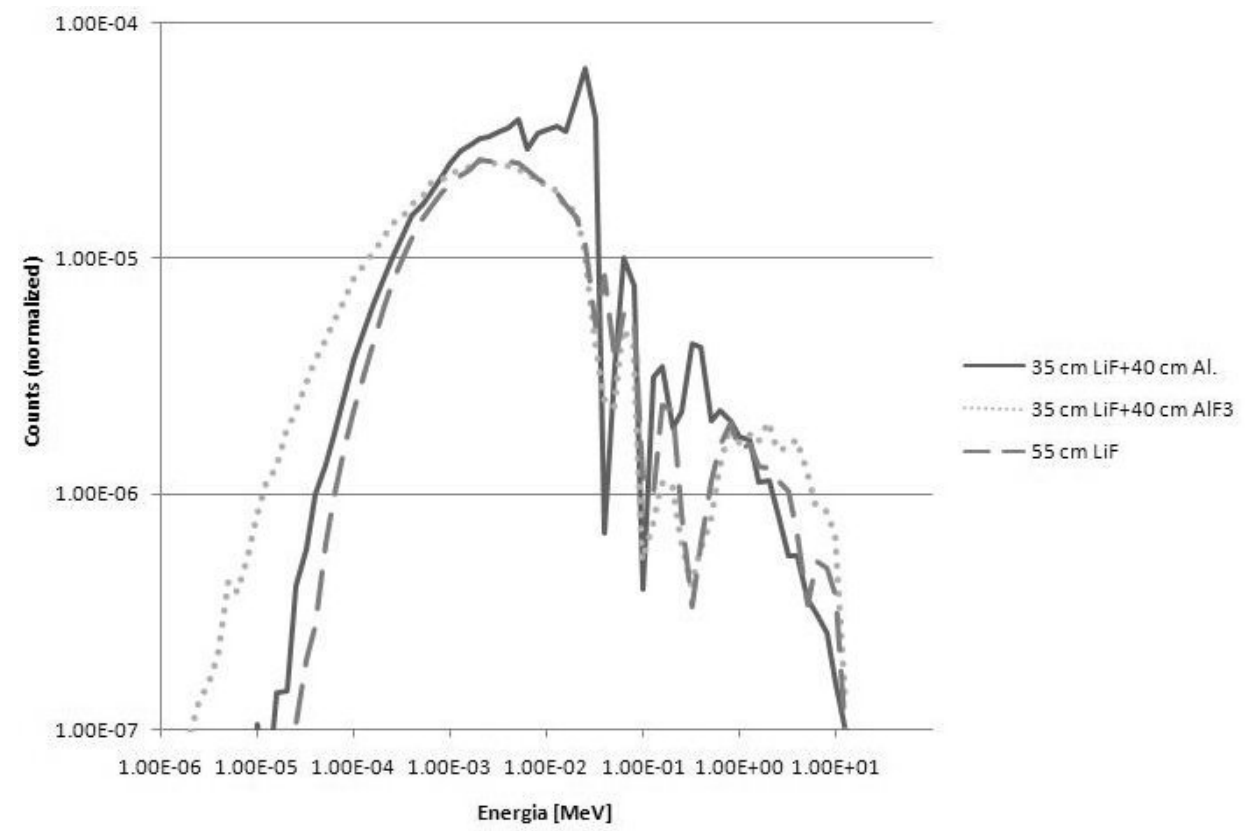

Figure 4. The comparison of neutron spectra from filters containing $\mathrm{Al}$ and one-layer $\mathrm{LiF}$ filter.

The ratio of epithermal to fast neutrons flux for the three versions of filters are presented in Table 1. 
Table 1. Epithermal to fast neutron flux ratio for spectra from filters containing $\mathrm{Al}$ and one-layer LiF filter. Values are for the data presented on Figure 4.

\begin{tabular}{||c|c|c|c||}
\hline Filter & $\begin{array}{c}\text { Epithermal neutrons } \\
\text { flux [arbitrary units] }\end{array}$ & $\begin{array}{c}\text { Fast neutron flux } \\
\text { [arbitrary units] }\end{array}$ & $\begin{array}{c}\text { Epithermal to } \\
\text { fast ratio }\end{array}$ \\
\hline \hline $35 \mathrm{~cm} \mathrm{LiF}+40 \mathrm{~cm} \mathrm{Al}$ & $4.84 \mathrm{E}-004$ & $2.78 \mathrm{E}-004$ & 1.74 \\
\hline $35 \mathrm{~cm} \mathrm{LiF}+40 \mathrm{~cm} \mathrm{AlF}_{3}$ & $4.37 \mathrm{E}-004$ & $1.06 \mathrm{E}-004$ & 4.13 \\
\hline $55 \mathrm{LiF}$ & $3.63 \mathrm{E}-004$ & $1.15 \mathrm{E}-004$ & 3.16 \\
\hline
\end{tabular}

Adding a layer of $\mathrm{Al}$ gives a relatively low value of the ratio. Adding $\mathrm{AlF}_{3}$ gives the biggest value of the ratio, but it is mostly because of the big number of neutrons with energies below $100 \mathrm{eV}$. This material reduces most efficiently neutrons with energies between approx. $10 \mathrm{keV}$ and $1 \mathrm{MeV}$, while the $\mathrm{LiF}$ filter reduces efficiently more harmful neutrons with energies above $1 \mathrm{MeV}$.

The next layer of the filter/moderator system is made of titanium. The cross section for this material is relatively low in most of the investigated energy range, but it has a peak at approx. $10 \mathrm{keV}$, capturing the neutrons from this energy range. $1 \mathrm{~cm}$ of titanium reduces very efficiently the number of neutrons of energies about $10 \mathrm{keV}$.

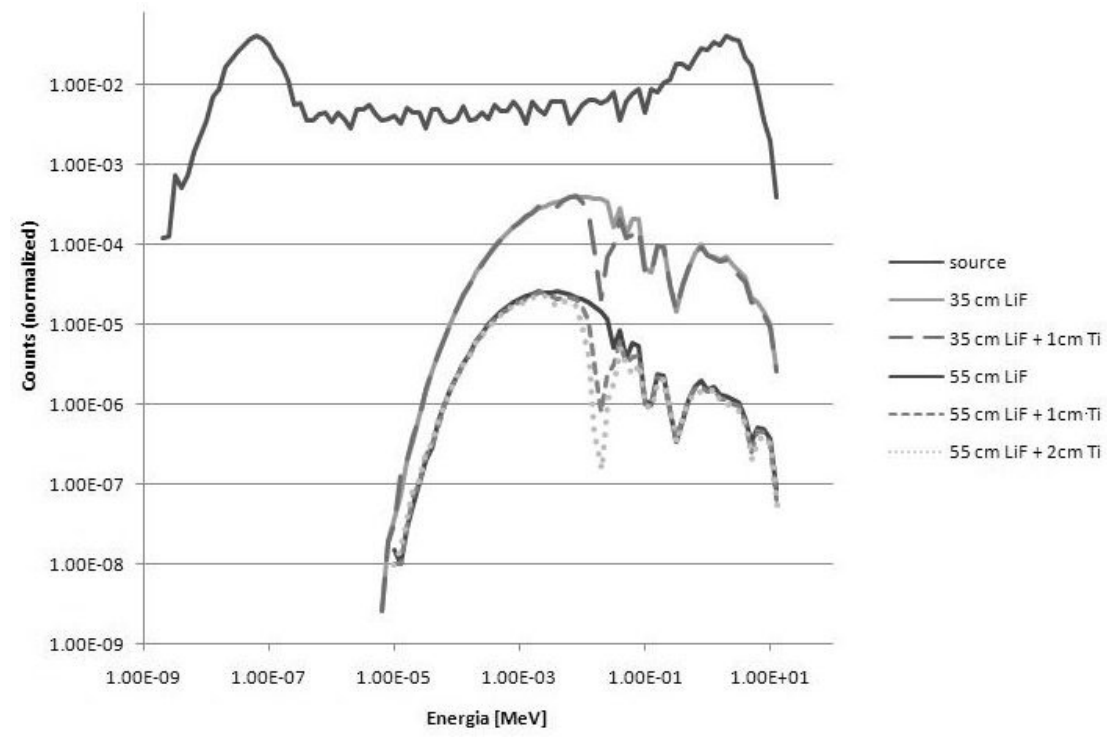

Figure 5. The influence of $1 \mathrm{~cm}$ Ti layer placed after LiF layer of 35 and $55 \mathrm{~cm}$. 
In order to reduce the number of neutrons with energies below $1 \mathrm{keV}$, we proposed using a thin layer of a material of a very high cross section for reactions caused by low energy neutrons. $2 \mathrm{~mm}$ layer of $\mathrm{B}_{4} \mathrm{C}$ reduces effectively the number of neutrons with energies below approx $100 \mathrm{eV}$. In calculation we used the density value taken from literature [3], in experiment the factual value may be lower, so it will be necessary to increase the thickness of the layer to obtain the same result.

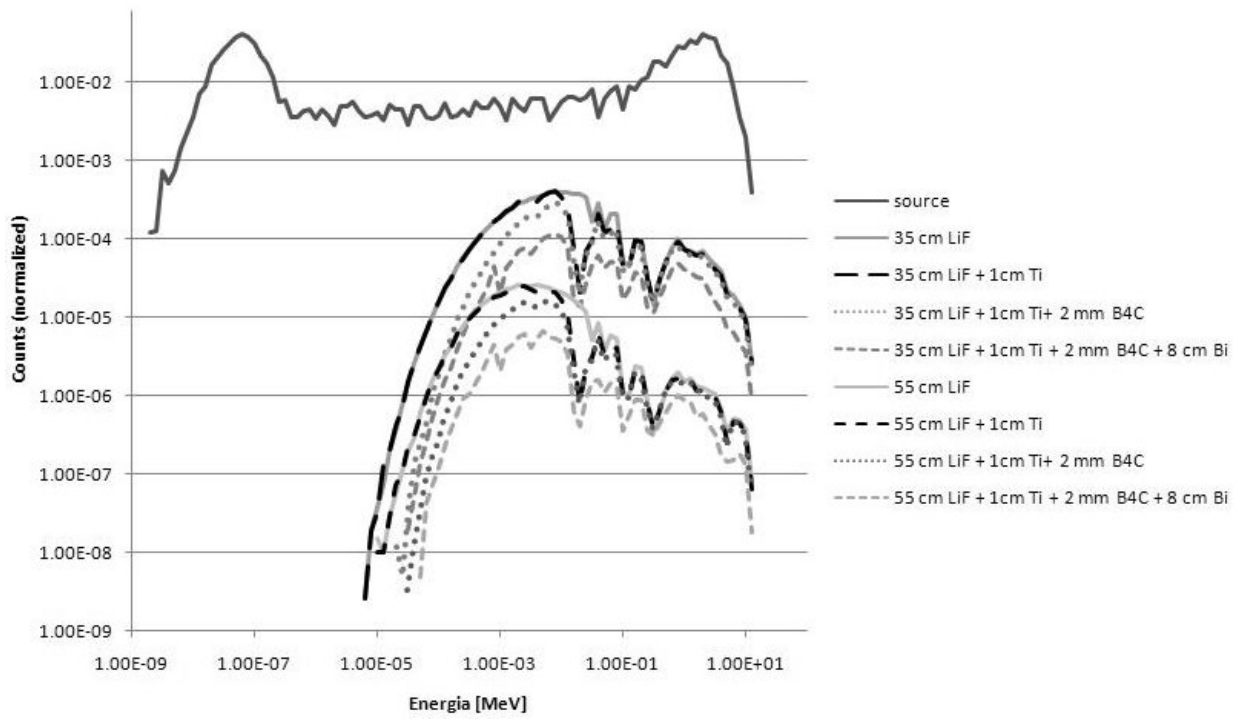

Figure 6. The neutron spectrum calculated for each of four layers of $\mathrm{LiF}+\mathrm{Ti}+\mathrm{B}_{4} \mathrm{C}+\mathrm{Bi}$ filters. Two values of $\mathrm{LiF}$ layer depths were tested $-35 \mathrm{~cm}$ (upper set of lines) and $55 \mathrm{~cm}$ (lower set of lines). The rest of layers $\left(\mathrm{Ti}, \mathrm{B}_{4} \mathrm{C}\right.$ and $\left.\mathrm{Bi}\right)$ have the same thickness in both cases $(1$ $\mathrm{cm}, 2 \mathrm{~mm}$ and $8 \mathrm{~cm}$ respectively).

Table 2. Epithermal to fast neutron ratio for spectra from two filters with different thickness of the LiF layer. Values for the data presented on Figure 6.

\begin{tabular}{|c|c|c|c|}
\hline Filter & $\begin{array}{c}\text { Epithermal neutrons } \\
\text { flux [arbitrary units] }\end{array}$ & $\begin{array}{c}\text { Fast neutron flux } \\
\text { [arbitrary units] }\end{array}$ & $\begin{array}{c}\text { Epithermal to } \\
\text { fast ratio }\end{array}$ \\
\hline \hline $\begin{array}{c}35 \mathrm{~cm} \mathrm{LiF}+1 \mathrm{~cm} \mathrm{Ti}+ \\
2 \mathrm{~mm} \mathrm{~B} \mathrm{C}_{4}+8 \mathrm{~cm} \mathrm{Bi}\end{array}$ & $9.67 \mathrm{E}-004$ & $8.75 \mathrm{E}-004$ & 1.11 \\
\hline $\begin{array}{c}55 \mathrm{~cm} \mathrm{LiF}+1 \mathrm{~cm} \mathrm{Ti}+ \\
2 \mathrm{~mm} \mathrm{~B} \mathrm{~B}_{4} \mathrm{C}+8 \mathrm{~cm} \mathrm{Bi}\end{array}$ & $6.85 \mathrm{E}-005$ & $2.29 \mathrm{E}-005$ & 2.99 \\
\hline
\end{tabular}


The last layer is a gamma filter made of $8 \mathrm{~cm}$ of $\mathrm{Bi}$. Its influence on neutron energy spectrum is unprofitable, but its presence is necessary in order to protect the patient from gamma radiation.

\section{Conclusions}

The ratio of epithermal to fast neutrons flux in 2 proposed versions of the filter is approx. 1 and 3 for LiF layer of 35 and $55 \mathrm{~cm}$ respectively.

According to recommendations of IAEA for BNCT [4], the desirable minimum beam intensity would be $10^{9}$ epithermal neutrons $\mathrm{cm}^{-2} \mathrm{~s}^{-1}$. Beams of $5-10^{8} \mathrm{n} \mathrm{cm}^{-2} \mathrm{~s}^{-1}$ are usable, but result in rather long irradiation times. When aiming at higher intensities $\left(>10^{10}\right)$ the advantages of shorter irradiation times must be weighed against those of improved beam quality. Where there is a choice to be made, most practitioners would rather have better quality rather than more intensity, within the constraint of having a reasonable treatment time (possibly extending up to one hour). Requiring immobilization of patients for significantly longer times reduces the clinical acceptability of BNCT as a therapy.

The results of MCNP calculations are normalized to one particle emitted from the source, so it is necessary to measure the actual neutron flux at $\mathrm{H}-2$ channel of Maria reactor in order to make a proper normalization to compare the model results with IAEA recommendations and chose the optimal thickness of the layers, especially the LiF layer.

Unfortunately, the works on the rearrangement of H-2 channel of MARIA reactor [2] are still in progress, making such a measurement impossible at the moment. As soon as possible, the measurements will be made, using activation foils method.

\section{Acknowledgements}

The work was supported by the Polish Ministry of Sciences and Higher Education, under grant No. PBZ/MEiN/01/2006/43. 


\section{References}

[1] Tyminska K. Monte Carlo calculations of epithermal and fast neutron dose in a human head model for Boron Neutron Capture Therapy. Pol J Med Phys Eng. 2008; 14(2): 79-85.

[2] Pytel K, Andrzejewski K, Owsianko I, Golnik N. A concept of the facility for Boron Neutron Capture therapy in MARIA reactor in Swierk. Recent Development and Applications of Nuclear Technologies, Bialowieza.

[3] MatWeb, Material Property Data, http://www.matweb.com/

[4] Current status of neutron capture therapy. IAEA, VIENNA, 2001, p.7. 